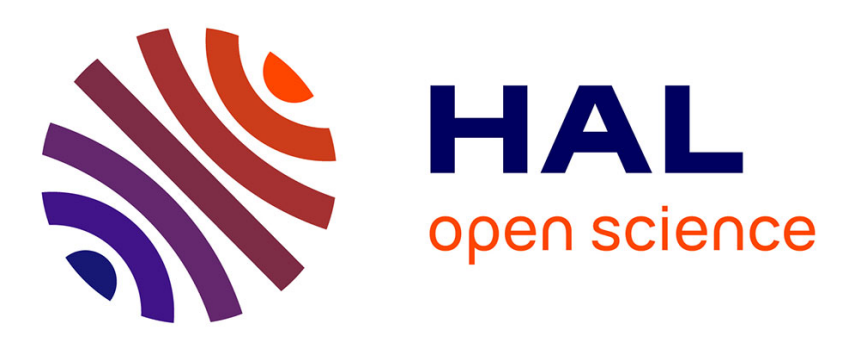

\title{
State-to-state modeling of a recombining nitrogen plasma experiment
}

\author{
C. Laux, Laurent Pierrot, Richard J. Gessman
}

\section{To cite this version:}

C. Laux, Laurent Pierrot, Richard J. Gessman. State-to-state modeling of a recombining nitrogen plasma experiment. Chemical Physics, 2011, 10 p. 10.1016/j.chemphys.2011.10.028 . hal-00669891

\section{HAL Id: hal-00669891 \\ https://hal.science/hal-00669891}

Submitted on 14 Feb 2012

HAL is a multi-disciplinary open access archive for the deposit and dissemination of scientific research documents, whether they are published or not. The documents may come from teaching and research institutions in France or abroad, or from public or private research centers.
L'archive ouverte pluridisciplinaire HAL, est destinée au dépôt et à la diffusion de documents scientifiques de niveau recherche, publiés ou non, émanant des établissements d'enseignement et de recherche français ou étrangers, des laboratoires publics ou privés. 
Accepté pour publication, Chemical Physics, Oct. 2011

\title{
State-to-state modeling of a recombining nitrogen plasma experiment
}

\author{
Christophe O. Laux, ${ }^{1,2,3}$ Laurent Pierrot, ${ }^{3}$ Richard J. Gessman ${ }^{3}$ \\ ${ }^{1}$ Laboratoire EM2C, CNRS UPR288, Grande Voie des Vignes, 92290 Châtenay-Malabry, France \\ ${ }^{2}$ Ecole Centrale Paris, Grande Voie des Vignes, 92290 Châtenay-Malabry, France \\ ${ }^{3}$ Mechanical Engineering Department, Stanford University, Stanford CA 94305, USA
}

\begin{abstract}
An atmospheric pressure nitrogen/argon plasma flows at high velocity through a water-cooled test-section in which it is forced to recombine within $250 \mu \mathrm{s}$. At the test-section inlet, the plasma is in Local Thermodynamic Equilibrium (LTE) at about $7200 \mathrm{~K}$. Because recombination rates are finite, the plasma reaches a state of chemical nonequilibrium at the exit of the test-section, at a temperature of about $4715 \mathrm{~K}$. At the test-section exit, the radiation emitted by the plasma, measured by emission spectroscopy, shows significant departures from equilibrium in the populations of the excited electronic states of nitrogen $\left(N_{2} B^{3} \Pi_{g}, N_{2} C^{3} \Pi_{u}\right)$ and of the nitrogen ion $\left(\mathrm{N}_{2}{ }^{+} \mathrm{B}^{2} \Sigma_{\mathrm{u}}{ }^{+}\right)$. This experiment is thus proposed as a test-case to validate collisional-radiative (CR) models. A vibrationally specific CR model is then used to predict the emission of these states. The rate coefficients of the model are calculated with the Weighted Rate Coefficient method based on elementary cross-section data. These rates depend explicitly on the kinetic temperatures of electrons $\left(T_{e}\right)$ and heavy species $\left(\mathrm{T}_{\mathrm{g}}\right)$. The predictions of the $\mathrm{CR}$ model are in good agreement with the measured vibrational population distribution in the $\mathrm{N}_{2}$ B state. A method is then proposed to determine ground state nitrogen atom densities based on the measured vibrational population distribution of the $\mathrm{N}_{2}$ B state.
\end{abstract}

\section{Introduction}

The chemistry of nonequilibrium molecular plasmas is important to predict nonequilibrium radiation in atmospheric re-entry and to interpret optical diagnostics in applications ranging from material processing or biodecontamination to plasma-assisted combution. Simulating the radiation of recombining plasmas or reentry flows requires to predict the populations of the emitting internal levels of atoms and molecules under nonequilibrium conditions. Various forms of nonequilibrium can exist. We distinguish thermal nonequilibrium, where the kinetic temperature $T_{g}$ of heavy species is different from the kinetic temperature $T_{e}$ of the electrons, and chemical nonequilibrium, where chemical reactions are not equilibrated. Local Thermodynamic Equilibrium (LTE) corresponds to the case of both thermal and chemical equilibrium. 
The nonequilibrium populations of internal energy states can be determined by solving the so-called master equation, which is a system of coupled state-specific rate equations (collisionalradiative model, or CR). While for atomic species it is usually sufficient to consider 10-100 electronic states, for molecular species a much larger number of rovibronic levels must be taken into account. Many CR models [1-5] use the simplifying assumption that the rotational and vibrational energy levels of molecules are populated according to Boltzmann distributions at temperatures $T_{r}$ and $T_{v}$, respectively. In these models, the master equation is solved for electronic levels only, with global rates corresponding to averages over the rovibrational states of each electronic level. Thus these approaches implicitly assume that departures from Boltzmann distributions in the populations of rotational and vibrational levels are small.

Yet, departures from Boltzmann distributions, at least in the vibrational levels, are fairly common. Experiments conducted at Stanford University [6] with a nitrogen/argon plasma forced to recombine within $250 \mu$ s from a state of equilibrium at a temperature of $7200 \mathrm{~K}$ to a state of chemical nonequilibrium at $4715 \mathrm{~K}$ have shown that the populations of vibrational levels in certain electronic states, in particular the $\mathrm{B}^{3} \Pi_{\mathrm{g}}$ of $\mathrm{N}_{2}$, can strongly depart from a Boltzmann distribution when the density of atomic nitrogen is higher than its LTE value. To predict nonequilibrium populations, a vibrational state-specific collisional-radiative (CR) model must be used. Most existing vibrational state-specific CR models [7-9] usually assume that the rotational levels follow a Boltzmann distribution owing to fast rotational relaxation, especially at atmospheric pressure. This assumption is also made in the present work.

In this paper, we first give an overview of the vibrational state-to-state $\mathrm{CR}$ model that we have developed for nitrogen plasmas [10-12]. The second part of the paper presents the recombining nitrogen plasma experiment [6] which is proposed as a test-case to validate nitrogen $\mathrm{CR}$ models. The third part compares the vibrational population distributions measured in that experiment with the simulations obtained with the nitrogen CR model. In the last part of the paper, we propose a method to determine absolute ground state $\mathrm{N}$ atom densities from the measured nonequilibrium emission of the $\mathrm{N}_{2}$ B state.

\section{Nitrogen CR model}

Details about the nitrogen $\mathrm{CR}$ model and derivation of the vibrational state-specific rate coefficients are given by Pierrot et al. [10-12]. This model was subsequently extended to air plasmas [13], but these extensions will not presented because the focus of the present paper is on modeling a recombining nitrogen plasma. We give below an overview of the nitrogen CR model and of its capabilities.

\section{Species and energy levels considered}

The species considered in the nitrogen CR model are $\mathrm{N}, \mathrm{N}^{+}, \mathrm{N}_{2}, \mathrm{~N}_{2}^{+}$, and electrons. The internal structure of $\mathrm{N}$ is accounted for by using the 22 grouped electronic levels of Park [14]. 
For $\mathrm{N}^{+}$, only the ground state is taken into account. The $\mathrm{X}, \mathrm{A}, \mathrm{B}, \mathrm{W}, \mathrm{B}^{\prime}$, and $\mathrm{C}$ electronic states of $\mathrm{N}_{2}$ and the $\mathrm{X}, \mathrm{A}$, and $\mathrm{B}$ electronic states of $\mathrm{N}_{2}^{+}$are included, and all rovibrational levels belonging to these states are considered up to the dissociation limit. As listed in [Insert Table 1, the model takes into account 192 vibronic levels of $\mathrm{N}_{2}$ and 142 levels of $\mathrm{N}_{2}{ }^{+}$. Note that the model for the ground state of $\mathrm{N}_{2}$ contains fewer vibrational levels that the more accurate model recently proposed by Le Roy et al [15] (48 levels for present model vs. 61 levels for Le Roy et $a l)$, but this difference has little impact on the excited state populations presented here.

\section{[Insert Table 1.]}

\section{Reactions considered}

The nitrogen CR model considers approximately 46,000 reactions that are summarized in [insert Table 2. These reactions include electron-impact ionization, excitation, and dissociation of atoms and molecules, heavy-particle impact dissociation of molecules, as well as electronimpact vibrational excitation of ground state nitrogen (VE transfer), vibrational-translational (VT) and vibrational-vibrational (VV) transfer, charge exchange, dissociative recombination, radiation, and predissociation.

\section{[insert Table 2]}

\section{Example of rate coefficient calculation: $N_{2}$ ground state ionization by electron impact}

To illustrate the principles of the vibrationally specific CR model, we present the method of calculation of the rate coefficients for electron-impact ionization of ground state $\mathrm{N}_{2}$. We begin by considering the elementary ionization reaction between rovibronic level (X,v",J") of $\mathrm{N}_{2}$ to level $\left(\mathrm{A}, \mathrm{v}^{\prime}, \mathrm{J}\right.$ ') of $\mathrm{N}_{2}^{+}$.

$$
\mathrm{N}_{2}\left(X, v^{\prime}, J^{\prime \prime}\right)+e \rightarrow \mathrm{N}_{2}^{+}\left(A, v^{\prime}, J^{\prime}\right)+e+e
$$

We first determine the rate coefficient of this elementary reaction, and then we average the elementary rate coefficients over all initial ( $\left.\mathrm{J}^{\prime \prime}\right)$ and final $(\mathrm{J}$ ') rotational levels of $(\mathrm{X}, \mathrm{v}$ ') and $\left(A, v^{\prime}\right)$ in order to obtain the vibrational state-specific rate coefficients.

\section{Elementary rate coefficients}

The elementary rate coefficient of electron-impact ionization of $\mathrm{N}_{2}$ (X,v",J") into $\mathrm{N}_{2}{ }^{+}$ $\left(\mathrm{A}, \mathrm{v}^{\prime}, \mathrm{J}^{\prime}\right)$, can be written as:

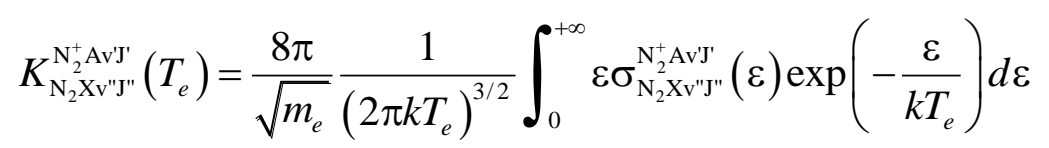

where $\sigma_{\mathrm{N}_{2} \mathrm{Xv} \mathrm{v}^{\prime \prime} \mathrm{J}^{\prime}}^{\mathrm{N}^{+} \mathrm{vv}^{\prime}}(\varepsilon)$ is the cross-section of the elementary reaction, $m_{e}$ the electron mass, and $\varepsilon$ the electron energy. In Eqn. (1), we have implicitly assumed that electrons follow a Maxwellian energy distribution at temperature $T_{e}$. In passing, we note that all rate coefficients of the CR 
model assume Maxwellian energy distributions for electrons and heavy species at $T_{e}$ and $T_{g}$, respectively. Although this assumption is not justified in general for electrons, we will see later that it is valid for the conditions of the recombination experiment presented in this paper.

Following Park [14], we consider that the Franck-Condon principle holds for transitions in molecules caused by collisions with electrons, and that no change in rotational quantum number occurs as a result of such collisions. Accordingly, we write the elementary cross-section of ionization from rovibronic level $\mathrm{N}_{2}\left(\mathrm{X}, \mathrm{v}^{\prime}, \mathrm{J}^{\prime \prime}\right)$ to rovibronic level $\mathrm{N}_{2}^{+}\left(\mathrm{A}^{\prime}, \mathrm{v}^{\prime}, \mathrm{J}\right.$ ') as:

$$
\sigma_{\mathrm{N}_{2} \mathrm{Xv} \mathrm{V}^{\prime \prime} J^{\prime \prime}}^{\mathrm{N}^{+} \mathrm{Av}^{\prime}}=q_{\mathrm{Xv}^{\prime \prime}}^{\mathrm{Av}^{\prime}} \delta_{J}^{J^{\prime}} \chi\left(\varepsilon, \Delta E_{\mathrm{Xv}^{\prime} \mathrm{v}^{\prime}}^{\mathrm{Av}^{\prime}{ }^{\prime}}\right)
$$

where $q_{\mathrm{Xv}^{\prime \prime}}^{\mathrm{Av}}$ designates the Franck-Condon factor, $\Delta E_{\mathrm{Xv}^{\prime \prime J}}^{\mathrm{Av}^{\prime} J^{\prime \prime}}$ the ionization energy, and $\delta_{J^{\prime \prime}}^{J^{\prime}}$ is equal to 1 if $\mathrm{J}^{\prime \prime}=\mathrm{J}$ ' and to 0 otherwise. The reduced cross-section $\chi\left(\varepsilon, \Delta E_{\mathrm{Xv}^{\prime \prime J} \mathrm{~J}^{\prime}}^{\mathrm{A}^{\prime}{ }^{\prime}}\right)$ is calculated with the Binary-Encounter-Bethe (BEB) model of Hwang et al [17], which provides ionization crosssections within $15 \%$ of experimental values for a wide variety of atoms and molecules. The BEB expression is:

$$
\chi\left(\varepsilon, \Delta E_{\mathrm{Xv}^{\prime} J^{\prime}}^{\mathrm{Av}}\right)=4 \pi a_{0}^{2} N\left(\frac{R}{\Delta E_{\mathrm{Xv}^{\prime} J^{\prime} J^{\prime}}^{\mathrm{Av^{ \prime }}}}\right)^{2} \frac{1}{t+u+1}\left[\frac{\ln t}{2}\left(1-\frac{1}{t^{2}}\right)+1-\frac{1}{t}-\frac{\ln t}{t+1}\right]
$$

where $R$ is the Rydberg constant $(13.61 \mathrm{eV}), a_{0}$ is the Bohr radius $(0.5292 \AA), N$ is the electron occupation number in the shell from which ionization takes place, $t$ stands for $\varepsilon / \Delta E_{\mathrm{Xv} \text { "J" }}^{\mathrm{Av} \prime}$ where $\varepsilon$ is the kinetic energy of the electron, and $u$ stands for $\mathrm{U} / \Delta E_{\mathrm{Xv}^{\prime \prime J "}}^{\mathrm{Av}^{\prime}{ }^{\prime}}$ where $\mathrm{U}$ is the average kinetic energy of a bound electron in the shell. The values of $\mathrm{N}$ and $\mathrm{U}$ are given by Hwang et al [17] for several molecular orbitals of $\mathrm{N}_{2}$ and $\mathrm{O}_{2}$.

\section{Vibrational state-specific rate coefficients}

To obtain the vibrational state-specific rate coefficients, we sum the elementary rate coefficients over all final rotational levels, and we average over the distribution of initial rotational levels. We assume that the initial rotational levels follow a Boltzmann distribution at rotational temperature $T_{r}$, which is a reasonable approximation for many molecules of interest (except perhaps the hydrides) owing to fast collisional relaxation at atmospheric pressure. The vibrational state specific rate coefficient is then:

$$
K_{\mathrm{N}_{2} \mathrm{Xv}^{\prime \prime}}^{\mathrm{N}^{+} \mathrm{Av}^{\prime}}\left(T_{e}, T_{r}\right)=\frac{1}{Q_{\mathrm{rot}}^{\mathrm{N}_{2} \mathrm{Xv}}\left(T_{r}\right)} \times \sum_{J "}\left(2 J^{\prime \prime}+1\right) \exp \left[-\frac{F_{\mathrm{N}_{2} \mathrm{Xv}^{\prime \prime}}\left(J^{\prime \prime}\right)}{k T_{r}}\right] \sum_{\mathrm{J}^{\prime}} K_{\mathrm{N}_{2} \mathrm{X} \mathrm{Xv}^{\prime \prime} J^{\prime \prime}}^{\mathrm{N}^{+} \mathrm{vv}^{\prime}}\left(T_{e}\right)
$$

where $Q_{\mathrm{rot}}^{N_{2}, X, \mathrm{v}^{\prime \prime}}$ is the rotational partition function of $\mathrm{N}_{2}$ in level $\mathrm{X}, \mathrm{v}$ ", and $F_{\mathrm{N}_{2} \mathrm{Xv}}\left(J^{\prime \prime}\right)$ is the rotational term energy of level $J$ '. The reverse rates are determined by detailed balance.

We compare in [insert Table 3 the total vibrationally specific ionization cross-sections of $\mathrm{N}_{2}\left(\mathrm{X}^{1} \Sigma_{\mathrm{g}}{ }^{+}, \mathrm{v}\right)$ with the values presented by Kosarim et al [26] in Figure 4 of their paper. As can 
be seen in [insert Table 3, the present model predicts a slight increase of the cross-sections with the electron impact energy, whereas the model of Kosarim et al [26] predicts the opposite. Nevertheless, reasonable agreement is obtained overall between the two models since the ionization cross-sections agree within $80 \%$ for $\mathrm{v}=0$, and within $30 \%$ for $\mathrm{v}=20$. It should be noted that the model of Kosarim et al [26] includes ionization to three states of $\mathrm{N}_{2}^{+}$, namely the $\mathrm{X}^{2} \Sigma_{\mathrm{g}}{ }^{+}$, $\mathrm{A}^{2} \Pi_{\mathrm{u}}$, and $\mathrm{B}^{2} \Sigma_{\mathrm{u}}{ }^{+}$states whereas the present model is limited to ionization into states $\mathrm{X}^{2} \Sigma_{\mathrm{g}}{ }^{+}$and $\mathrm{A}^{2} \Pi_{\mathrm{u}}$. However, according to $\mathrm{Van} \mathrm{Zyl}$ and Pendleton [27], the branching ratios of the ionization cross-sections from $\mathrm{N}_{2} \mathrm{X}$ to $\mathrm{N}_{2}{ }^{+} \mathrm{X}, \mathrm{N}_{2}{ }^{+} \mathrm{A}$, and $\mathrm{N}_{2}{ }^{+} \mathrm{B}$ are respectively equal to $0.320 \pm 01.47$, $0.535 \pm 0.112$, and $0.145 \pm 0.019$ for an electron impact energy of $100 \mathrm{eV}$. Thus, even at these high impact energies, the cross-section for ionization of $\mathrm{N}_{2}{ }^{+} \mathrm{B}$ represents less than $15 \%$ of the total ionization cross-section. Therefore, we do not expect ionization from the ground state of $\mathrm{N}_{2}$ to the B state of $\mathrm{N}_{2}{ }^{+}$to greatly affect the overall ionization.

\section{[insert Table 3]}

\section{Predissociation rates}

As will be seen in the analysis of the recombination experiments presented in Sections 3 and 4 , predissociation plays a key role on the vibrational population distribution of the $\mathrm{B}$ state of $\mathrm{N}_{2}$. Therefore, we describe here the method by which these rates are computed in the CR model.

The predissociation rate constants $\gamma(\mathrm{v}, J)$ of the $\mathrm{B}$ state of $\mathrm{N}_{2}$ are taken from Geisen et al [24]:

$$
\gamma(\mathrm{v}, J)=\gamma_{1}(\mathrm{v})+\gamma_{2}(\mathrm{v}) J(J+1)
$$

where the second term on the right hand side of Eqn. (5) is a corrective term corresponding to indirect predissociation of the ${ }^{3} \Pi_{0}{ }^{\mathrm{f}}$ component via rotational coupling with the ${ }^{3} \Pi_{1}{ }^{\text {ef }}$ components (the ${ }^{3} \Pi_{0}{ }^{\mathrm{f}}$ component would otherwise remain unpredissociated). This corrective term cannot be larger than the value $\gamma_{2}{ }^{\max }$ corresponding to the ${ }^{3} \Pi_{1}$ predissociation rate constant.

In our CR model, the total predissociation rate constant of a given level $\mathrm{v}$ is calculated as a function of $T_{r}$ by averaging the $J$-dependent values given by Eqn. (5) as follows:

$$
\bar{\gamma}(v)=\frac{1}{Q_{r o t}^{N_{2}(B, v)}\left(T_{r}\right)} \sum_{J \geq J_{\min }}(2 J+1) \exp \left(-F_{B v}(J) / k T_{r}\right) \gamma(v, J)
$$

where $J_{\min }$ is the minimum rotational quantum number for which the vibrational level considered predissociates. According to Lofthus and Krupenie [28], these values are $J_{\min }=32$ for $\mathrm{v}=12$ and $J_{\text {min }}=0$ for $\mathrm{v} \geq 13$. The summation over $J$ in Eqn. (6) is truncated at the limiting value $\gamma_{2}{ }^{\max }$. The values of $\gamma_{1}(\mathrm{v}), \gamma_{2}(\mathrm{v})$, and $\gamma_{2}{ }^{\max }$ are listed in [insert Table 4. When rate constants for a particular component of a given vibrational level are missing, they are taken as the average rate constants 
of that level. The predissociation rate constants of $\mathrm{v}=12$, not given by Geisen et $\mathrm{al}$, are assumed to be equal to those of $\mathrm{v}=13$.

\section{[insert Table 4]}

In summary, we have presented a vibrationally specific CR model for nitrogen plasmas. This model will be applied later in this paper to the analysis of the recombining nitrogen plasma experiment presented next.

\section{Nonequilibrium recombining nitrogen plasma experiment}

Experiments were conducted at Stanford University [6] with a recombining atmospheric pressure nitrogen plasma. The experimental set-up is shown in [insert Figure 1 . In these experiments, a mixture of $\sim 100 \mathrm{slpm} \mathrm{N}_{2}, \sim 50 \mathrm{slpm}$ argon, and $\sim 2.3 \mathrm{slpm} \mathrm{H}_{2}$ was inductively heated with a $50 \mathrm{~kW}$ RF plasma torch. Argon was added to stabilize the torch operating conditions, and $\mathrm{H}_{2}$ was added in order to measure the electron number density from the Starkbroadened $\mathrm{H}_{\beta}$ line. The plasma produced by the torch was accelerated to a velocity of $\sim 1 \mathrm{~km} / \mathrm{s}$ by passing through a $1 \mathrm{~cm}$ diameter torch exit nozzle. From the nozzle, the plasma was then rapidly cooled (within $\sim 250 \mu \mathrm{s}$ ) by flowing through a $15 \mathrm{~cm}$-long water-cooled brass testsection. A shorter test-section, $10 \mathrm{~cm}$ in length, was also used to obtain intermediate results at a distance of $10 \mathrm{~cm}$ from the nozzle exit. Calorimetric measurements were taken on the water flow used to cool the 10 and $15 \mathrm{~cm}$ test-sections. The total heat flux removed by the testsections was 2.4 and $4.5 \mathrm{~kW}( \pm 0.1 \mathrm{~kW})$ for the 10 - and 15 -cm test-sections, respectively.

\section{[insert Figure 1.]}

Emission spectroscopy measurements were made using a SPEX model 750M, 0.75-meter, scanning monochromator fitted with a Hamamatsu model R1104 photomultiplier tube. Two 1200 lines/mm gratings blazed at 200 and $500 \mathrm{~nm}$ were used to cover the spectral range of the present study. The entrance and exit slits of the monochromator were set to 200 and $400 \mu \mathrm{m}$, respectively, yielding a trapezoidal slit function of base $0.66 \mathrm{~nm}$ and top $0.22 \mathrm{~nm}$. The spectra measured along the diameter of the plasma at the nozzle and test-section exits were calibrated in absolute intensity using two NIST traceable radiance standards: an Optronics model OL550 standard for wavelengths between 300 and $800 \mathrm{~nm}$ and a 1-kW Argon Mini-Arc from Arc Applications Research between 200 and $400 \mathrm{~nm}$.

At the exit of the nozzle (position termed $0 \mathrm{~cm}$ ), several temperature profiles were obtained by Abel-inverting absolute intensity profiles of various emission lines of $\mathrm{N}$, Ar, and $\mathrm{H}$ [6]. As can be seen from Fig. 2a, the good agreement among the various temperature profiles indicates that the plasma is close to LTE at the nozzle exit (which is the inlet of the test-section). The maximum temperature at the centerline is approximately $7200 \mathrm{~K}$. A similar technique was applied at the exit of the $10 \mathrm{~cm}$ nozzle (Fig. 2b). At the exit of the 15-cm test-section, a 
temperature profile was measured by Abel-inverting lateral profiles of the $(0,0)$ band of the $\mathrm{N}_{2}{ }^{+}$ first negative system, as described also in Ref. [6]. The centerline temperature was found to be $4715 \pm 100 \mathrm{~K}$ (Fig. 2c). Subsequent high-resolution spectroscopy measurements [29] using resolved rotational lines of the $\mathrm{N}_{2}{ }^{+}$first negative system confirmed these measurements with a measured centerline temperature of $4850 \pm 100 \mathrm{~K}$.

\section{[insert Figure 2]}

At $7200 \mathrm{~K}$, the LTE composition of the plasma is $55 \% \mathrm{~N}, 19 \% \mathrm{~N}_{2}$, with a balance of argon and hydrogen. The electron mole fraction is $5.5 \times 10^{-4}$. At $4715 \mathrm{~K}$, the LTE composition is $63 \%$ $\mathrm{N}_{2}, 1.3 \% \mathrm{~N}$, with a balance of argon and hydrogen, and an electron mole fraction of $3.4 \times 10^{-7}$. However, because the plasma residence time within the $15-\mathrm{cm}$ test section, $250 \mu \mathrm{s}$, is shorter than the characteristic time of atomic nitrogen recombination [30], the atomic nitrogen population tends to freeze and hence is expected to be higher than its LTE value at the exit of the 15 -cm test-section.

Electron number densities were also measured using the Stark broadened $\mathrm{H}_{\beta}$ line at $486 \mathrm{~nm}$, using the technique described in Ref. [31]. The resulting values at 0,10 and $15 \mathrm{~cm}$ are compared in [insert Table 5 with the corresponding LTE number densities at these locations. As can be seen from the table, the electron number density remains close to LTE until at least the exit of the $10 \mathrm{~cm}$ test-section. On the other hand, the measured electron number density at $15 \mathrm{~cm}$ is about two orders of magnitude larger than the LTE value, consistent with the existence of nonequilibrium conditions at that location.

\section{[insert Table 5]}

We now examine the emission spectra at the various locations. Absolute emission spectra between 280 and $800 \mathrm{~nm}$ were measured along the plasma diameter, both at the nozzle exit and at the test-section exits. These measured spectra were then compared with LTE spectra calculated with the line-by-line radiation code SPECAIR [31] using the measured gas temperature profiles.

At the nozzle exit, the measured and LTE spectra are in close agreement (see

[insert Figure 3), which supports the existence of LTE conditions at the nozzle exit. At the 10-cm test section exit, the comparison also indicates that the plasma remains close to LTE. At the $15-\mathrm{cm}$ test-section exit, however, the measured spectrum is more intense than the computed LTE spectrum (see [insert Figure 4). In particular, the radiative emission of the first positive system of $\mathrm{N}_{2}$, second positive system of $\mathrm{N}_{2}$, and first negative system of $\mathrm{N}_{2}{ }^{+}$is higher than LTE values by factors of about 6, 30, and 10, respectively. These differences indicate that the populations of the emitting vibrational levels are higher than the corresponding LTE values, and thus that these levels follow nonequilibrium distributions. We will now extract the 
nonequilibrium vibrational distributions from the measured spectra in order to provide quantitative data to test the CR model.

Note that several bands of $\mathrm{NH} \mathrm{A-X}$ and $\mathrm{OH}$ A-X, the latter coming from some entrainment of ambient air into the plasma plume, were observed in the spectra, and that these bands interfere with the bands of the second positive system of $\mathrm{N}_{2}$ (C-B transition) and of the first positive system of $\mathrm{N}_{2}{ }^{+}$(B-X). For clarity, we have excluded from [insert Figure 4 the regions where these bands appear, but details of the analysis including these bands are given in Appendix A.

\section{[insert Figure 3]}

\section{[insert Figure 4]}

The nonequilibrium vibrational population distributions of the observed emitting states at the 15-cm test-section exit were examined. To this end, we multiplied the LTE populations of individual vibrational levels by nonequilibrium factors in SPECAIR, until the predicted spectrum (obtained by solving the radiative transport equation along the plasma diameter) matched the measured spectrum (see Figure 5). Note that this procedure assumes that the nonequilibrium factors are uniform along the plasma diameter. However, because the line-of-sight emission is strongly dominated by the emission from the central region of the plasma, the inferred nonequilibrium factors closely reflect the nonequilibrium population distribution at the center of the plasma. These nonequilibrium factors are defined by:

$$
\rho_{\mathrm{v}}=\frac{\mathrm{n}_{\mathrm{v}}^{\text {measured }}}{\mathrm{n}_{\mathrm{v}}^{\text {LTE }}}
$$

where $\mathrm{n}_{\mathrm{v}}{ }^{\text {measured }}$ and $\mathrm{n}_{\mathrm{v}}{ }^{\mathrm{LTE}}$ stand respectively for the measured and equilibrium (at the local gas temperature) number density in level $\mathrm{v}$ of the $\mathrm{B}$ state of $\mathrm{N}_{2}$. Hence, a nonequilibrium factor greater than unity implies that the vibrational level $\mathrm{v}$ is overpopulated with respect to equilibrium at the local gas temperature.

\section{[insert Figure 5]}

The measured distribution of nonequilibrium population factors of the $\mathrm{N}_{2} \mathrm{~B}$ and $\mathrm{C}$ states and of the $\mathrm{N}_{2}{ }^{+} \mathrm{B}$ state are shown in [insert Figure 6. In this graph, a Boltzmann distribution at $\mathrm{T}_{\mathrm{v}}=$ $4715 \mathrm{~K}$ would be represented by the straight line $\rho_{\mathrm{v}}=1$. For the $\mathrm{N}_{2} \mathrm{C}$ and $\mathrm{N}_{2}{ }^{+} \mathrm{B}$ states, the inferred overpopulation factors do not vary much with the vibrational levels, with values of about 30 for the $\mathrm{N}_{2} \mathrm{C}$ state and 11 for the $\mathrm{N}_{2}{ }^{+} \mathrm{B}$ state. For the $\mathrm{N}_{2} \mathrm{~B}$ state, the measured vibrational distribution is non-Boltzmann, with a marked peak at $\mathrm{v}=13$. We will now compare these measurements with the predictions of the CR model for the B and C states of $\mathrm{N}_{2}$. 


\section{[insert Figure 6]}

\section{Analysis of the recombining nitrogen experiments}

The nitrogen CR model is used in this section to analyze the recombining nitrogen plasma experiments. We are particularly interested in the nonequilibrium vibrational distribution of the B state of $\mathrm{N}_{2}$, which exhibits a peculiar dependence with a peak at $\mathrm{v}=13$. Argon is not included in the CR model, and we make the assumption that it does not significantly affect the populations of the observed nitrogen states. We therefore consider the case of a pure nitrogen plasma in chemical nonequilibrium. The CR model calculations are performed by making use of the quasisteady-state (QSS) approximation, which assumes that all excited levels of atoms and molecules are in steady-state, and equations relative to ground levels are replaced with mass conservation equations.

The input parameters of the model are the temperature $T=4715 \mathrm{~K}$, the pressure $p=1 \mathrm{~atm}$, and the number densities of the different species $\left(\mathrm{e}, \mathrm{N}_{2}, \mathrm{~N}_{2}{ }^{+}, \mathrm{N}\right.$, and $\left.\mathrm{N}^{+}\right)$at the exit of the 15-cm test-section. The electron number density was measured from the Stark-broadened $\mathrm{H}_{\beta}$ line and was found to be $7.3 \times 10^{13} \mathrm{~cm}^{-3}$. The $\mathrm{N}$ atom overpopulation factor (recall that we expect an overpopulation of nitrogen atoms owing to the finite rate of nitrogen recombination) has been adjusted to $\rho_{\mathrm{N}}=8.1$ in order to obtain the best possible agreement with the peak of the distribution at $\mathrm{v}=13$. This value will be justified later in Section 4. Thus the $\mathrm{N}$ density is set to $1.5 \times 10^{17} \mathrm{~cm}^{-3}$. The density of $\mathrm{N}_{2}$ is assumed to stay close to its LTE value. Finally, the densities of $\mathrm{N}^{+}$and $\mathrm{N}_{2}{ }^{+}$are chosen in such a way that the plasma is electrically neutral and that the charge exchange reaction $\mathrm{N}_{2}+\mathrm{N}^{+} \leftrightarrow \mathrm{N}_{2}{ }^{+}+\mathrm{N}$ is balanced. Note however that the densities of $\mathrm{N}^{+}$and $\mathrm{N}_{2}{ }^{+}$ have little influence on the $\mathrm{N}_{2} \mathrm{~B}$ state population. The final set of input parameters for the $\mathrm{CR}$ model computations at $15 \mathrm{~cm}$ is summarized in [insert Table 6.

In general, superelastic and electron-electron collisions can have a strong influence on the electron energy distribution function of nitrogen plasmas at low translational temperatures [32, 33]. However, for the conditions of this experiment, the electron density distribution function can be considered to be Maxwellian, as shown by Capitelli et al [34]. This observation justifies our assumption in the CR model of a Maxwellian electron energy distribution for the calculation of electron-impact rate coefficients.

\section{[insert Table 6]}

The computed vibrational overpopulation factors of the $\mathrm{B}$ state of $\mathrm{N}_{2}$ are plotted in [insert Figure 7 together with the measured overpopulation factors. The curve labeled "CR model" was obtained using the baseline rate coefficients of the CR model. This calculation reproduces the general shape of the experimental curve, with a peak at $v=13$, but predicts larger overpopulation 
factors at v's above and below 13. Thus we examined the sensitivity of the CR model predictions by varying selected rates.

Curve (a) was calculated by multiplying the $\mathrm{N}_{2}(\mathrm{X}-\mathrm{A})$ and $\mathrm{N}_{2}(\mathrm{X}-\mathrm{B})$ electron-impact excitation and de-excitation rates by a factor of 4 , and by dividing the predissociation rate of level $\mathrm{N}_{2}(\mathrm{~B}, \mathrm{v}=12)$ by a factor of 5 . Note that the value of the $\mathrm{N}_{2}(\mathrm{~B}, \mathrm{v}=12)$ predissociation rate used in the baseline CR model is an estimate based on the value measured by Geisen et al. [24] for $\mathrm{v}=13$, so that the foregoing adjustment to the rate is reasonable. Similarly, the multiplicative factor of 4 for the $\mathrm{X}-\mathrm{A}$ and $\mathrm{X}-\mathrm{B}$ excitation rates is not unreasonable, given the uncertainty on cross-sections for these reactions [35]. With these modified rates, good agreement is obtained with the experimental curve for $\mathrm{v}=0-13$.

Curve (b) presents another calculation in which the rates are modified as in curve (a) and predissociation of levels $\mathrm{v} \geq 14$ is neglected. Better agreement with the experimental curve is now obtained for the high-lying levels $v \geq 14$. This result may suggest that the predissociation rates of levels $v \geq 14$ are overestimated in the model, but it may also be due to uncertainties on other rates. The SSH-based VT transfer rate, for instance, may be somewhat inaccurate for the high lying levels, and multi-quantum jumps may have to be considered although typically they should be unimportant at the relatively low temperatures considered here [36, 37]. Nevertheless, these discrepancies are not significant because the experimental uncertainties on overpopulation factors of high-lying levels $v \geq 15$ are quite large (see [insert Figure 6).

\section{[insert Figure 7]}

The CR model also predicts the populations of additional vibronic states. [insert Figure 8 shows the vibrational overpopulation factors of the $\mathrm{X}, \mathrm{A}, \mathrm{B}, \mathrm{W}, \mathrm{B}^{\prime}$, and $\mathrm{C}$ states of $\mathrm{N}_{2}$ as a function of the vibrational quantum number $\mathrm{v}$, calculated with the same modified rates as curve (a) of [insert Figure 7. The predicted overpopulation factors for the low-lying levels of all states are in the range 2 to 4 . The overpopulation factors of the $\mathrm{X}, \mathrm{A}$, and $\mathrm{C}$ states increase steadily with $\mathrm{v}$ to reach values close to 66 , i.e. corresponding to dissociation equilibrium (by this, we mean that the last vibrational level below the dissociation limit of a given electronic state is nearly in equilibrium with the dissociation products). The measured overpopulation factors of the $\mathrm{C}$ state of $\mathrm{N}_{2}$ are practically constant with $\mathrm{v}$, whereas the $\mathrm{CR}$ model predicts a sharp increase with $\mathrm{v}$. One possible explanation is that we may overestimate the degree of coupling between the last level $(\mathrm{v}=4)$ with nitrogen atoms. In the baseline model, we have simply considered that this level, which is known to be subject to predissociation [28], is fully coupled with the atoms. This assumption appears to be too strong. In addition, it seems important to incorporate in the model the rates of quenching by heavy-particle impact, as well as the rates of $\mathrm{V}-\mathrm{T}$ and $\mathrm{V}-\mathrm{V}$ transfer for the $\mathrm{C}$ (and B) states of $\mathrm{N}_{2}$. According to the measurements of Dilecce et al [38, 39], these rates are relatively fast and thus could flatten the overpopulation distribution in the $\mathrm{C}$ state 
of $\mathrm{N}_{2}$. Finally, the $\mathrm{W}$ state overpopulation curve exhibits two inflexion points, and the $\mathrm{B}^{\prime}$ state overpopulation curve has a local maximum similar to that of the B state. These behaviors are caused by collisional coupling with the predissociating levels of the B state.

\section{[insert Figure 8]}

\section{Method for measuring $\mathbf{N}$ atom densities by emission spectroscopy}

Despite the remaining uncertainties on the shape of the vibrational population distribution, the results obtained with the baseline $\mathrm{CR}$ model reproduce the observed nonequilibrium distribution of the $\mathrm{N}_{2}$ B state reasonably well. An interesting result of the analysis presented in the previous section is that vibrational level $v=13$ of the $B$ state of $N_{2}$ appears to be fully coupled with $\mathrm{N}$ atoms by predissociation and inverse predissociation. This can be seen by writing the rate equation at steady-state for the population of $\mathrm{N}_{2}, \mathrm{~B}, \mathrm{v}=13$ :

$$
\begin{aligned}
& \frac{d n_{N_{2}, B, 13}}{d t}=0=-n_{N_{2}, B, 13}\left\{k_{\mathrm{v}=13}^{\text {pred }}+\sum_{\mathrm{v}^{\prime \prime}} A_{13 \mathrm{v}^{\prime \prime}}+n_{M}\left(k_{V T}^{13 \rightarrow 14}+k_{V T}^{13 \rightarrow 12}\right)+n_{e} k_{i o n}^{e}+\sum_{Y=X, A, B^{\prime}, W, C} n_{e} k_{B, 13 \rightarrow Y}^{e}\right\} \\
& +n_{N}^{2} k_{\mathrm{v}=13}^{i n v \cdot p r .}+\sum_{\mathrm{Y}^{\prime}, \mathrm{v}^{\prime}} n_{N_{2}, Y^{\prime}, \mathrm{v}^{\prime}} A_{\mathrm{v}^{\prime} 13}+n_{N_{2}, B, 14} n_{M} k_{V T}^{14 \rightarrow 13}+n_{N_{2}, B, 12} n_{M} k_{V T}^{12 \rightarrow 13}+n_{e}^{2} n_{N_{2}^{+}} k_{r e c}^{e}+\sum_{Y=X, A, B^{\prime}, W, C} n_{Y} n_{e} k_{Y \rightarrow B, 13}^{e}
\end{aligned}
$$

The numerical values of the depleting terms that appear in the first bracket, as calculated with the CR model, are listed in

[insert Table 7.

\section{[insert Table 7]}

It can be seen from

[insert Table 7 that the predissociation term is about 30 times larger than the sum of the other depletion terms. Similarly, it can be shown that the largest term among the processes populating $\mathrm{B}, \mathrm{v}=13$ is the inverse predissociation term. It follows that, at steady-state, Eqn. (8) can be approximated by:

$$
n_{N_{2}, B, 13} k_{\mathrm{v}=13}^{\text {pred }} \approx\left(n_{N}\right)^{2} k_{\mathrm{v}=13}^{\text {inv.pred }}
$$

Using superscript $e q$ to designate equilibrium densities, we also have, from detailed balance, the following relation:

$$
n_{N_{2}, B, 13}^{e q} k_{\mathrm{v}=13}^{\text {pred }}=\left(n_{N}^{e q}\right)^{2} k_{\mathrm{v}=13}^{\text {inv. pred }}
$$

Dividing Eqn. (9) by Eqn. (10), we obtain:

$$
n_{N_{2}, B, 13} / n_{N_{2}, B, 13}^{e q} \approx\left(n_{N} / n_{N}^{e q}\right)^{2}
$$


which, using nonequilibrium factor notation, can finally be written as:

$$
\rho_{N_{2}, B, 13} \approx \rho_{N}^{2}
$$

Equation (12) expresses a very interesting relation, namely that the overpopulation of the $\mathrm{N}_{2, \mathrm{~B}, \mathrm{v}=13}$ state is approximately equal to the square of the overpopulation factor of atomic nitrogen in the ground state. In other words, the vibrational state $v=13$ is in partial equilibrium with nitrogen atoms in their ground state (in the same way as the last vibrational level in any electronic state tends to be in partial equilibrium with the dissociation products issued from this given state). This relation means that it is possible to use emission spectroscopy to infer ground state atomic nitrogen densities. For our experimental conditions, the overpopulation factor of $\mathrm{v}=13$ is measured to be $\rho_{\mathrm{N} 2, \mathrm{~B}, \mathrm{v}=13}=66 \pm 4$. Thus the overpopulation of nitrogen atoms is approximately $8.1 \pm 0.3$. At $4715 \pm 100 \mathrm{~K}$, the equilibrium density of nitrogen atoms in the nitrogen/argon plasma mixture is $1.8 \pm 0.4 \times 10^{16} \mathrm{~cm}^{-3}$. Multiplying this number by the measured overpopulation factor $\rho_{N}$, we infer a nonequilibrium nitrogen atom density of $1.5 \pm 0.4 \times 10^{17} \mathrm{~cm}^{-3}$, which corresponds to a mole faction of about $10 \%$ (whereas the LTE mole fraction of atomic nitrogen at $4715 \mathrm{~K}$ is only $1.3 \%$ ). Note that relation (13) is also valid at pressures lower than one atmosphere because the various depletion terms decrease with decreasing pressure and therefore become even more negligible relative to the rate of predissociation. Thus this technique provides a way to measure absolute densities of ground state nitrogen atoms using emission spectroscopy. It could be particularly useful to determine the density of nitrogen atoms in recombining plasmas such as those produced in arcjets.

\section{Conclusions}

Because the characterization of re-entry flow radiation by onboard detectors can only be conveniently performed using optical emission spectroscopy, accurate CR models are needed to infer species densities and temperatures from emission measurements. Collisional-radiative models have recently emerged that can predict certain nonequilibrium plasma conditions reasonably well. In this paper, we described a detailed vibrationally specific CR model and we showed how it can be used to understand and predict the nonequilibrium radiation emitted by a recombining nitrogen plasma at atmospheric pressure. One important result was that the nonequilibrium emission from the $\mathrm{N}_{2} \mathrm{~B}$ state can be used to measure the density of ground state atomic nitrogen, hence the dissociation fraction of nitrogen in the flow-field. This method complements existing techniques such as VUV absorption and Two-photon Absorption LaserInduced Fluorescence (TALIF). In addition, we have provided an experimental test-case with a plasma flow under well-characterized thermodynamic conditions and with detailed quantitative measurements of nonequilibrium vibrational population distributions in the B and C states of $\mathrm{N}_{2}$ and in the $\mathrm{B}$ state of $\mathrm{N}_{2}{ }^{+}$. These data can be used to test advanced CR models. 
Uncertainties remain on many of the state-specific reaction rates. Accurate cross-sections are needed, in particular for state-specific electron and heavy-particle impact dissociation and excitation rate coefficients. At low pressure, it is also important to take into account possible departures from a Maxwellian distribution for the free electrons. Finally, additional quantitative measurements in nonequilibrium flows are required to further test and validate the nonequilibrium CR models.

\section{Appendix A}

In this appendix, details about the fitting of the nonequilibrium spectra at the exit of the 15 $\mathrm{cm}$ test-section are presented. The radiative transitions considered in this analysis are the $\mathrm{N}_{2}$ first (B-A) and second (C-B) positive systems, the $\mathrm{N}_{2}{ }^{+}$first negative system (B-X), the (A-X) transition of $\mathrm{OH}$, and the $(\mathrm{A}-\mathrm{X})$ transition of $\mathrm{NH}$. The $\mathrm{OH}$ and $\mathrm{NH}$ vibrational populations were arbitrarily adjusted to match the features due to these systems in the experimental spectra. Detailed fits over the spectral region 280-470 nm are shown in Figure A.1. The main bands are identified in Table A.1.

[insert Figure A.1]

[insert Table A.1.]

\section{Acknowledgments}

Financial support from the US Air Force Office of Scientific Research, NASA Ames Research Center, the European Space Agency, and the French Ministry of Research (Chaire d'Excellence) is gratefully acknowledged.

\section{References}

[1] J. Bacri, A. Medani, Physica C, 112 (1982) 101-118.

[2] C. Park, Nonequilibrium Air Radiation (NEQAIR) Program: User's Manual, in, NASA-Ames Research Center, Moffett Field, CA, 1985.

[3] J.P. Sarrette, A.M. Gomes, J. Bacri, C.O. Laux, C.H. Kruger, JQSRT, 53 (1995) 143-152.

[4] J.P. Sarrette, A.M. Gomès, J. Bacri, C.O. Laux, C.H. Kruger, JQSRT, 53 (1995) 125-141.

[5] P. Teulet, S. J.-P., A.-M. Gomès, JQSRT, 70 (2001) 159-187.

[6] R.J. Gessman, C.O. Laux, C.H. Kruger, Experimental study of kinetic mechanisms of recombining atmospheric pressure air plasmas, in: 28th AIAA Plasmadynamics and Lasers Conference, Atlanta, GA, 1997.

[7] M. Cacciatore, M. Capitelli, C. Gorse, Chemical Physics, 66 (1982) 141-151.

[8] G. Colonna, M. Capitelli, D. Giordano, State to State Electron and Vibrational Kinetics in Supersonic Nozzle Expansion: an Improved Model, in: 33rd AIAA Plasmadynamics and Lasers Conference, Maui, HW, 2002. 
[9] J. Loureiro, C.M. Ferreira, Journal of Physics D, 22 (1989) 67-75.

[10] L. Pierrot, C.O. Laux, C.H. Kruger, Vibrationally-Specific Collisional-Radiative Model for Nonequilibrium Nitrogen Plasmas, in: 29th AIAA Plasmadynamics and Lasers Conference, Albuquerque, NM, 1998.

[11] L. Pierrot, L. Yu, R.J. Gessman, C.O. Laux, C.H. Kruger, Collisional-radiative modeling of nonequilibrium effects in nitrogen plasmas, in: 30th AIAA Plasmadynamics and Lasers Conference, Norfolk, VA, 1999.

[12] L. Pierrot, Chemical Kinerics and Vibrationally Specific Collisional-Radiative Models for Nonequilibrium Nitrogen Plasmas, in, Stanford University, 1999.

[13] S.M. Chauveau, C.O. Laux, J.D. Kelley, C.H. Kruger, Vibrationally Specific CollisionalRadiative Model for Nonequilibrium Air Plasmas, in: 33rd AIAA Plasmadynamics and Lasers Conference, Maui, HW, 2002.

[14] C. Park, Nonequilibrium Hypersonic Aerothermodynamics, Wiley, New York, 1989.

[15] R.J. Le Roy, Y. Huang, C. Jary, Journal of Chemical Physics, 125 (2006) 164310.

[16] J. Bacri, A. Medani, Physica C, 101 (1980) 399-409.

[17] W. Hwang, Y.-K. Kim, M.E. Rudd, J. Chem. Phys., 104 (1996) 2956-2966.

[18] T. Majeed, D.J. Strickland, J. Phys. Chem. Ref. Data, 26 (1997) 335-349.

[19] J.R. Peterson, A. Le Padellec, H. Danared, G.H. Dunn, M. Larrson, A. Larson, R. Peverall, C.S.R. Stromhlom, M. af Ugglas, W.J. van der Zande, Journal of Chemical Physics, 108 (1998) 1978-1988.

[20] R.F. Stebbings, B.R. Turner, A.C.H. Smith, Journal of Chemical Physics, 38 (1963) 2277.

[21] D.C. Cartwright, S. Trajmar, A. Chutjian, W. Williams, Physical Review A, 16 (1977) 1041-1051.

[22] M.J. Seaton, The Theory of Excitation and Ionization by Electron Impact, in: D.R. Bates (Ed.) Atomic and Molecular Processes, Academic Press, 1962, pp. 375-420.

[23] Y.K. Kazansky, I.S. Yelets, J. Phys. B, 17 (1984) 4767-4783.

[24] H. Geisen, D. Neuschäfer, C. Ottinger, Journal of Chemical Physics, 92 (1990) 104-115.

[25] C.O. Laux, C.H. Kruger, JQSRT, 48 (1992) 9-24.

[26] A.V. Kosarim, B.M. Smirnov, M. Capitelli, R. Celiberto, G. Petrella, A. Laricchiuta, Chemical Physics Letters, 414 (2005) 215-221.

[27] B. Van Zyl, W. Pendleton Jr., Journal of Geophysical Research, 100 (1995) 23755-23762.

[28] A. Lofthus, P.H. Krupenie, J. Phys. Chem. Ref. Data, 6 (1977) 113.

[29] C.O. Laux, R.J. Gessman, C.H. Kruger, F. Roux, F. Michaud, S.P. Davis, JQSRT, 68 (2001) 473-482.

[30] R.J. Gessman, An Experimental Investigation of the Effects of Chemical and Ionizational Nonequilibrium in Recombining Air Plasmas, in: Mechanical Engineering Dept., Stanford University, Stanford, CA, 2000.

[31] C.O. Laux, T.G. Spence, C.H. Kruger, R.N. Zare, Plasma Sources Science and Technology, 12 (2003) 125-138.

[32] C. Gorse, M. Cacciatore, M. Capitelli, S. De Benedictis, G. Dilecce, Chemical Physics, 119 (1988) 63-70. 
[33] G. Colonna, C. Gorse, M. Capitelli, R. Winkler, J. Wilhelm, Chemical Physics Letters, 213 (1993) 5-9.

[34] M. Capitelli, S. Longo, N. Dyatko, K. Hassouni, Journal of Thermophysics and Heat Transfer, 12 (1998) 478-481

[35] J. Bacri, A. Medani, Physica C, 101 (1980) 410-419.

[36] F. Esposito, I. Armenise, M. Capitelli, Chemical Physics, 331 (2006) 1-8.

[37] F. Esposito, M. Capitelli, Chemical Physics Letters, 418 (2006) 581-585.

[38] G. Dilecce, P.F. Ambrico, S. De Benedictis, Plasma Sources Science and Technology, 16 (2007) S45-S51.

[39] G. Dilecce, P.F. Ambrico, S. De Benedictis, Chemical Physics Letters, 431 (2006) 241-246. 
Table 8. Rovibronic states of $\mathrm{N}_{2}$ and $\mathrm{N}_{2}{ }^{+}$in the nitrogen $\mathrm{CR}$ model. $J_{\max }$ is the highest rotational level considered in the ground vibrational level.

\begin{tabular}{lll|lll}
\hline \multicolumn{2}{c|}{$\mathrm{N}_{2}$} & \multicolumn{3}{c}{$\mathrm{N}_{2}^{+}$} \\
\hline Electronic state & $\begin{array}{l}\text { Vibrational } \\
\text { levels }\end{array}$ & $\mathrm{J}_{\max }$ & Electronic state & $\begin{array}{l}\text { Vibrational } \\
\text { levels }\end{array}$ & $\mathrm{J}_{\max }$ \\
\hline $\mathrm{X}^{1} \Sigma_{\mathrm{g}}^{+}$ & $0-47$ & 268 & $\mathrm{X}^{2} \Sigma_{\mathrm{g}}^{+}$ & $0-52$ & 253 \\
$\mathrm{~A}^{3} \Sigma_{\mathrm{u}}^{+}$ & $0-27$ & 194 & $\mathrm{~A}^{2} \Pi_{\mathrm{u}}$ & $0-63$ & 246 \\
$\mathrm{~B}^{3} \Pi_{\mathrm{g}}$ & $0-30$ & 212 & $\mathrm{~B}^{2} \Sigma_{\mathrm{u}}^{+}$ & $0-24$ & 208 \\
$\mathrm{~W}^{3} \Delta_{\mathrm{u}}$ & $0-37$ & 218 & & & \\
$\mathrm{~B}^{3} \Sigma_{\mathrm{u}}^{-}$ & $0-41$ & 225 & & & \\
$\mathrm{C}^{3} \Pi_{\mathrm{u}}$ & $0-4$ & 136 & & & \\
\hline
\end{tabular}


Table 9. Reactions considered in the nitrogen $\mathrm{CR}$ model. $\mathrm{X}$ stands for the ground electronic state of a given species. Y', Y' refer to any electronic state of molecules. Z', Z' refer to any electronic state of atoms. M stands for any heavy collider $\left(\mathrm{N}, \mathrm{N}^{+}, \mathrm{N}_{2}\right.$, or $\left.\mathrm{N}_{\mathbf{2}}^{+}\right)$.

\begin{tabular}{|c|c|c|}
\hline Reaction & $\begin{array}{l}\text { Cross-section or } \\
\text { rate coefficient data }\end{array}$ & Remarks \\
\hline \multicolumn{3}{|l|}{ Ionization } \\
\hline $\mathrm{N}\left(Z^{\prime \prime}\right)+\mathrm{e} \leftrightarrow \mathrm{N}^{+}(\mathrm{X})+\mathrm{e}+\mathrm{e}$ & Drawin [16] & \\
\hline $\mathrm{N}_{2}\left(\mathrm{Y}^{\prime \prime}, \mathrm{v}^{\prime \prime}\right)+\mathrm{e} \leftrightarrow \mathrm{N}_{2}^{+}\left(\mathrm{Y}^{\prime}, \mathrm{v}^{\prime}\right)+\mathrm{e}+\mathrm{e}$ & BEB [17] & $\begin{array}{l}\mathrm{X} \rightarrow \mathrm{X}, \mathrm{X} \rightarrow \mathrm{A}, \mathrm{A} \rightarrow \mathrm{A}, \\
\mathrm{B} \rightarrow \mathrm{X}, \mathrm{W} \rightarrow \mathrm{A}, \mathrm{B}^{\prime} \rightarrow \mathrm{A}, \\
\mathrm{C} \rightarrow \mathrm{B}\end{array}$ \\
\hline \multicolumn{3}{|l|}{ Dissociation } \\
\hline $\mathrm{N}_{2}\left(X, \mathrm{v}^{\prime \prime}\right)+\mathrm{e} \leftrightarrow \mathrm{N}(\mathrm{X})+\mathrm{N}(\mathrm{X})+\mathrm{e}$ & Majeed [18] & Ground state only \\
\hline $\mathrm{N}_{2}(\mathrm{X}, \mathrm{v} ")+\mathrm{M} \leftrightarrow \mathrm{N}(\mathrm{X})+\mathrm{N}(\mathrm{X})+\mathrm{M}$ & Park [14] & $\mathrm{M}=\mathrm{N}$ or $\mathrm{N}_{2}$ \\
\hline \multirow[t]{2}{*}{$\mathrm{N}_{2}\left(Y^{\prime \prime}, \mathrm{v}^{\prime \prime}\right)+\mathrm{M} \leftrightarrow \mathrm{N}(Z)+\mathrm{N}\left(Z^{\prime}\right)+\mathrm{M}$} & $\mathrm{V}-\mathrm{T}$ and $\mathrm{V}-\mathrm{V}$ transfer to & $\mathrm{M}=\mathrm{N}, \mathrm{N}^{+}, \mathrm{N}_{2}, \mathrm{~N}_{2}^{+}$ \\
\hline & the last vibrational level & $\mathrm{Y}^{\prime \prime}=\mathrm{A}, \mathrm{B}, \mathrm{W}, \mathrm{B}, \mathrm{C}$ \\
\hline \multirow[t]{2}{*}{$\mathrm{N}_{2}^{+}\left(\mathrm{Y}^{\prime \prime}, \mathrm{v}^{\prime \prime}\right)+\mathrm{M} \leftrightarrow \mathrm{N}(\mathrm{Z})+\mathrm{N}^{+}(\mathrm{X})+\mathrm{M}$} & below dissociation & $\mathrm{M}=\mathrm{N}, \mathrm{N}^{+}, \mathrm{N}_{2}, \mathrm{~N}_{2}^{+}$ \\
\hline & limit & $\mathrm{Y}^{\prime \prime}=\mathrm{X}, \mathrm{A}, \mathrm{B}$ \\
\hline \multicolumn{3}{|l|}{ Dissociative recombination } \\
\hline $\mathrm{N}_{2}^{+}(\mathrm{X}, \mathrm{v} ")+\mathrm{e} \leftrightarrow \mathrm{N}(\mathrm{X})+\mathrm{N}(\mathrm{X})$ & Peterson [19] & Ground state only \\
\hline \multicolumn{3}{|l|}{ Charge exchange } \\
\hline $\mathrm{N}_{2}\left(\mathrm{X}, \mathrm{v}^{\prime \prime}\right)+\mathrm{N}^{+}(\mathrm{X}) \leftrightarrow \mathrm{N}_{2}^{+}\left(\mathrm{X}, \mathrm{v}^{\prime}\right)+\mathrm{N}(\mathrm{X})$ & Stebbings [20] & Ground state only \\
\hline \multicolumn{3}{|l|}{ Electronic excitation } \\
\hline $\mathrm{N}\left(Z^{\prime \prime}\right)+\mathrm{e} \leftrightarrow \mathrm{N}\left(Z^{\prime}\right)+\mathrm{e}$ & Park [14] & \\
\hline $\mathrm{N}_{2}\left(\mathrm{X}, \mathrm{v}^{\prime \prime}\right)+\mathrm{e} \leftrightarrow \mathrm{N}_{2}\left(\mathrm{Y}^{\prime}, \mathrm{v}^{\prime}\right)+\mathrm{e}$ & Cartwright [21] & $\mathrm{Y}^{\prime}=\mathrm{A}, \mathrm{B}, \mathrm{W}, \mathrm{B}^{\prime}, \mathrm{C}$ \\
\hline $\mathrm{N}_{2}\left(\mathrm{Y}^{\prime \prime}, \mathrm{v}^{\prime \prime}\right)+\mathrm{e} \leftrightarrow \mathrm{N}_{2}\left(\mathrm{Y}^{\prime}, \mathrm{v}^{\prime}\right)+\mathrm{e}$ & Seaton [22], Drawin [16] & $\mathrm{Y}, \mathrm{Y}^{\prime}=\mathrm{A}, \mathrm{B}, \mathrm{W}, \mathrm{B}^{\prime}, \mathrm{C}$ \\
\hline $\mathrm{N}_{2}^{+}\left(\mathrm{Y}^{\prime \prime}, \mathrm{v}^{\prime \prime}\right)+\mathrm{e} \leftrightarrow \mathrm{N}_{2}^{+}\left(\mathrm{Y}^{\prime}, \mathrm{v}^{\prime}\right)+\mathrm{e}$ & Seaton [22], Drawin [16] & $\mathrm{Y}, \mathrm{Y}^{\prime}=\mathrm{X}, \mathrm{A}, \mathrm{B}$ \\
\hline \multicolumn{3}{|l|}{ Vibrational excitation } \\
\hline $\mathrm{N}_{2}\left(\mathrm{X}, \mathrm{v}^{\prime \prime}\right)+\mathrm{e} \leftrightarrow \mathrm{N}_{2}\left(\mathrm{X}, \mathrm{v}^{\prime}\right)+\mathrm{e}$ & Kazansky [23] (VE) & Ground state only \\
\hline $\mathrm{N}_{2}\left(\mathrm{Y}^{\prime \prime}, \mathrm{v} "\right)+\mathrm{M} \leftrightarrow \mathrm{N}_{2}(\mathrm{Y},, \mathrm{v} "+1)+\mathrm{M}$ & SSH model (VT) & $\mathrm{M}=\mathrm{N}, \mathrm{N}^{+}, \mathrm{N}_{2}, \mathrm{~N}_{2}^{+}$ \\
\hline $\mathrm{N}_{2}^{+}\left(\mathrm{Y}^{\prime \prime}, \mathrm{v} "\right)+\mathrm{M} \leftrightarrow \mathrm{N}_{2}^{+}\left(\mathrm{Y}^{\prime \prime}, \mathrm{v} "+1\right)+\mathrm{M}$ & SSH model (VT) & $\mathrm{M}=\mathrm{N}, \mathrm{N}^{+}, \mathrm{N}_{2}, \mathrm{~N}_{2}^{+}$ \\
\hline $\mathrm{N}_{2}\left(\mathrm{X}, \mathrm{v}_{1}\right)+\mathrm{N}_{2}\left(\mathrm{X}, \mathrm{v}_{2}\right) \leftrightarrow \mathrm{N}_{2}\left(\mathrm{X}, \mathrm{v}_{1}-1\right)+\mathrm{N}_{2}\left(\mathrm{X}, \mathrm{v}_{2}+1\right)$ & SSH model (VV) & Ground state only \\
\hline $\mathrm{N}_{2}^{+}\left(\mathrm{X}, \mathrm{v}_{1}\right)+\mathrm{N}_{2}^{+}\left(\mathrm{X}, \mathrm{v}_{2}\right) \leftrightarrow \mathrm{N}_{2}^{+}\left(\mathrm{X}, \mathrm{v}_{1}-1\right)+\mathrm{N}_{2}^{+}\left(\mathrm{X}, \mathrm{v}_{2}+1\right)$ & SSH model (VV) & Ground state only \\
\hline \multicolumn{3}{|l|}{ Predissociation } \\
\hline $\mathrm{N}_{2}(\mathrm{~B}, 12 \leq \mathrm{v} \leq 18) \leftrightarrow \mathrm{N}(\mathrm{X})+\mathrm{N}(\mathrm{X})$ & Geisen [24] & \\
\hline $\mathrm{N}_{2}(\mathrm{C}, \mathrm{v}=4) \leftrightarrow \mathrm{N}(\mathrm{X})+\mathrm{N}(\mathrm{X})$ & & Equilibrium with $\mathrm{N}(\mathrm{X})$ \\
\hline \multicolumn{3}{|l|}{ Radiation } \\
\hline $\mathrm{N}\left(Z^{\prime}\right) \leftrightarrow \mathrm{N}\left(Z^{\prime \prime}\right)+\mathrm{h} v$ & Park [14] & \\
\hline $\mathrm{N}_{2}\left(\mathrm{Y}^{\prime}, \mathrm{v}^{\prime}\right) \leftrightarrow \mathrm{N}_{2}\left(\mathrm{Y}^{\prime \prime}, \mathrm{v}^{\prime \prime}\right)+\mathrm{h} v$ & Laux [25] & \\
\hline $\mathrm{N}_{2}^{+}\left(\mathrm{Y}^{\prime}, \mathrm{v}^{\prime}\right) \leftrightarrow \mathrm{N}_{2}^{+}\left(\mathrm{Y}^{\prime \prime}, \mathrm{v}^{\prime \prime}\right)+\mathrm{hv}$ & Laux [25] & \\
\hline
\end{tabular}


Table 10. Comparison of vibrationally specific cross-sections for the ionization of levels $v=0$ and $v=20$ of the ground state of $\mathrm{N}_{2}$, as a function of the impacting electron energy, $E=20,30,50$ and $100 \mathrm{eV}$.

\begin{tabular}{|c|l|c|c|c|c|}
\hline \multirow{2}{*}{$\mathrm{v}=0$} & $\begin{array}{c}\sigma(\mathrm{E}=20 \mathrm{eV}) \\
\times 10^{-21} \mathrm{~m}^{2}\end{array}$ & $\begin{array}{c}\sigma(\mathrm{E}=30 \mathrm{eV}) \\
\times 10^{-21} \mathrm{~m}^{2}\end{array}$ & $\begin{array}{c}\sigma(\mathrm{E}=50 \mathrm{eV}) \\
\times 10^{-21} \mathrm{~m}^{2}\end{array}$ & $\begin{array}{c}\sigma(\mathrm{E}=100 \mathrm{eV}) \\
\times 10^{-21} \mathrm{~m}^{2}\end{array}$ \\
\hline \multirow{2}{*}{$\mathrm{v}=20$} & 3.2 & 10.9 & 17.9 & 20.4 \\
\cline { 2 - 6 } & Present work & 1.74 & 6.1 & 10.9 & \\
\cline { 2 - 6 } & Kosarim et al $[26]$ & 3.9 & 9.3 & 13.8 & 15.1 \\
\cline { 2 - 6 } & Kosarimt work et al $[26]$ & 2.9 & 7.5 & 12.2 & \\
\hline
\end{tabular}


Table 11. Predissociation rate constants for $\mathrm{N}_{2}(\mathrm{~B}, \mathrm{v})$ (from Geisen et al [24])

\begin{tabular}{|c|c|c|c|}
\hline $\mathrm{v}$ & $\gamma_{1}\left(\mathrm{~s}^{-1}\right)$ & $\gamma_{2}\left(\mathrm{~s}^{-1}\right)$ & $\gamma_{2}{ }^{\max }\left(\mathrm{s}^{-1}\right)$ \\
\hline 12 & $2.6 \times 10^{8}$ & $1.2 \times 10^{5}$ & $5.1 \times 10^{7}$ \\
\hline 13 & $2.6 \times 10^{8}$ & $1.2 \times 10^{5}$ & $5.1 \times 10^{7}$ \\
\hline 14 & $1.6 \times 10^{8}$ & $5.4 \times 10^{4}$ & $2.5 \times 10^{7}$ \\
\hline 15 & $1.1 \times 10^{8}$ & $3.2 \times 10^{4}$ & $1.5 \times 10^{7}$ \\
\hline 16 & $2.5 \times 10^{7}$ & $8.9 \times 10^{3}$ & $4.3 \times 10^{6}$ \\
\hline 17 & $7 \times 10^{6}$ & $5.1 \times 10^{2}$ & $2.5 \times 10^{5}$ \\
\hline 18 & $4 \times 10^{6}$ & $1.5 \times 10^{3}$ & $7.5 \times 10^{5}$ \\
\hline
\end{tabular}


Table 12. Measured and equilibrium electron number densities $\left(\mathrm{cm}^{-3}\right)$ for the $\mathrm{N}_{2} / \mathrm{Ar}$ plasma experiments

\begin{tabular}{llll}
\hline & $0 \mathrm{~cm}$ & $10 \mathrm{~cm}$ & $15 \mathrm{~cm}$ \\
\hline Measured & $5.0 \pm 0.3 \times 10^{14}$ & $9.8 \pm 1.8 \times 10^{13}$ & $7.3 \pm 4.0 \times 10^{13}$ \\
Equilibrium $^{*}$ & $5.4 \pm 0.4 \times 10^{14}$ & $6.4 \pm 2.0 \times 10^{13}$ & $5.3 \pm 2.7 \times 10^{11}$ \\
\hline
\end{tabular}

*equilibrium is taken at the local gas temperature and 1 atm. 
Table 13. Species densities used to simulate the recombining nitrogen plasma conditions at the exit of the $15-\mathrm{cm}$ test-section. $T=4715 \mathrm{~K}, \mathrm{P}=1 \mathrm{~atm}$.

\begin{tabular}{llll}
\hline $\mathrm{S}$ & $\mathrm{n}_{\mathrm{S}}{ }^{\mathrm{eq}}\left(\mathrm{cm}^{-3}\right)$ & $\mathrm{n}_{\mathrm{S}}\left(\mathrm{cm}^{-3}\right)$ & $\rho_{\mathrm{S}}$ \\
\hline $\mathrm{N}$ & $1.8 \times 10^{16}$ & $1.5 \times 10^{17}$ & 8.1 \\
$\mathrm{~N}^{+}$ & $4.8 \times 10^{10}$ & $3.8 \times 10^{13}$ & $\sim 800$ \\
$\mathrm{~N}_{2}$ & $1.5 \times 10^{18}$ & $1.5 \times 10^{18}$ & 1 \\
$\mathrm{~N}_{2}{ }^{+}$ & $3.5 \times 10^{11}$ & $3.5 \times 10^{13}$ & 100 \\
$\mathrm{E}$ & $4.0 \times 10^{11}$ & $7.3 \times 10^{13}$ & 180 \\
\hline
\end{tabular}


Table 14. Reaction rates (normalized by the population of $\mathbf{n}_{\mathrm{N} 2, \mathrm{~B}, \mathrm{v}=-13}$ ) for the major depletion processes of $\mathbf{N}_{2}$ $(B, v=13)$ in the recombining nitrogen plasma $\left(T=4720 \mathrm{~K}, P=1 \mathrm{~atm}, \rho_{\mathrm{e}}=180, \rho_{\mathrm{N}}=8.1\right)$.

\begin{tabular}{lll}
\hline Term from Eqn. (6) & $\mathrm{s}^{-1}$ & Process \\
\hline$k_{\mathrm{v}=13}^{\text {pred }}$ & $2.6 \times 10^{8}$ & Predissociation \\
$\sum A_{13 \mathrm{v}^{\prime \prime}}$ & $2.0 \times 10^{6}$ & Radiation \\
$n_{M}\left(k_{V T}^{13 \rightarrow 14}+k_{V T}^{13 \rightarrow 12}\right)$ & $6 \times 10^{6}$ & Vibrational-translational excitation \\
$n_{e} k_{i o n}^{e}$ & Negligible & Electron impact ionization \\
$n_{e} k_{B, 13 \rightarrow X}^{e}$ & $3.7 \times 10^{4}$ & Electron impact excitation to $\mathrm{X}$ state \\
$n_{e} k_{B, 13 \rightarrow A}^{e}$ & $3.7 \times 10^{5}$ & Electron impact excitation to A state \\
$n_{e} k_{B, 13 \rightarrow W}^{e}$ & $3.7 \times 10^{6}$ & Electron impact excitation to $\mathrm{W}$ state \\
$n_{e} k_{B, 13 \rightarrow B^{\prime}}^{e}$ & $3.8 \times 10^{4}$ & Electron impact excitation to $\mathrm{B}$ ' state \\
$n_{e} k_{B, 13 \rightarrow C}^{e}$ & 60 & Electron impact excitation to C state \\
\hline
\end{tabular}


Table A.1. Vibrational bands of the $\mathrm{N}_{2} \mathrm{C}-\mathrm{B}$ (second positive) and $\mathrm{N}_{2}{ }^{+} \mathrm{B}-\mathrm{X}$ (first negative) systems used to extract the overpopulation factors of the vibrational levels of the $\mathrm{N}_{2} \mathrm{C}$ and $\mathrm{N}_{2}{ }^{+} \mathrm{B}$ states, as shown in Figures $6 \mathrm{a}$ and $6 \mathrm{~b}$. These bands can be identified on Figure A.1.

\begin{tabular}{|c|c|c|}
\hline $\mathrm{v}$ (emitting level) & Bands of the $\mathrm{N}_{2}$ C-B system & Bands of the $\mathrm{N}_{2}{ }^{+} \mathrm{B}-\mathrm{X}$ system \\
\hline 0 & $(0,1)-357.7 \mathrm{~nm}$ & $(0,0)-391.1 \mathrm{~nm}$ \\
& $(0,2)-380.4 \mathrm{~nm}$ & $(0,1)-427.5 \mathrm{~nm}$ \\
& $(0,3)-405.8 \mathrm{~nm}$ & $(1,0)-357.9 \mathrm{~nm}$ \\
& $(1,0)-315.8 \mathrm{~nm}$ & $(1,1)-388.1 \mathrm{~nm}$ \\
& $(1,3)-375.4 \mathrm{~nm}$ & $(1,2)-423.3 \mathrm{~nm}$ \\
\hline 1 & $(1,4)-399.7 \mathrm{~nm}$ & $(2,1)-356.1 \mathrm{~nm}$ \\
& $(2,0)-297.5 \mathrm{~nm}$ & $(2,3)-419.6 \mathrm{~nm}$ \\
\hline 2 & $(2,4)-370.9 \mathrm{~nm}$ & $(3,2)-354.6 \mathrm{~nm}$ \\
\hline 3 & $(2,5)-394.1 \mathrm{~nm}$ & \\
\hline 4 & $(3,1)-296.1 \mathrm{~nm}$ & \\
\hline
\end{tabular}




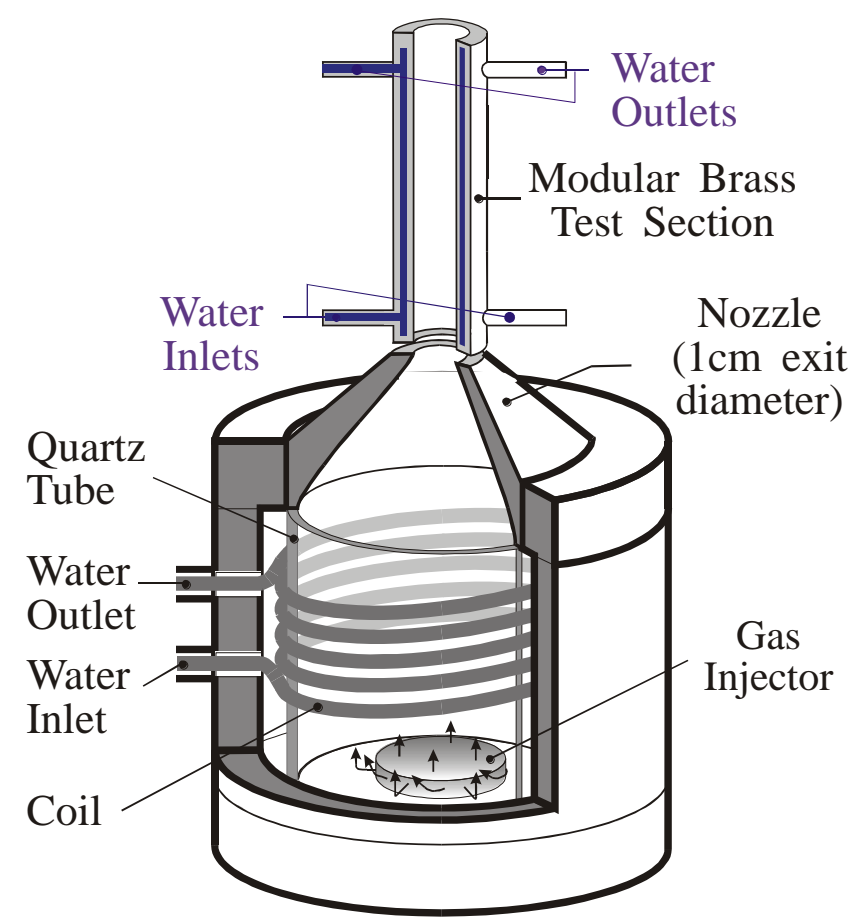

Figure 9. Schematic cross-section of torch head with test-section. 


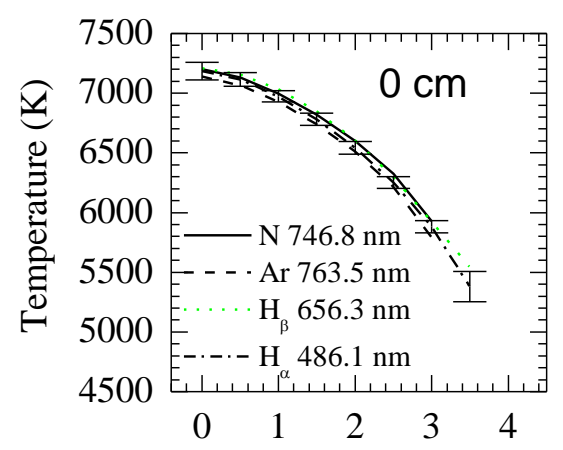

(a)

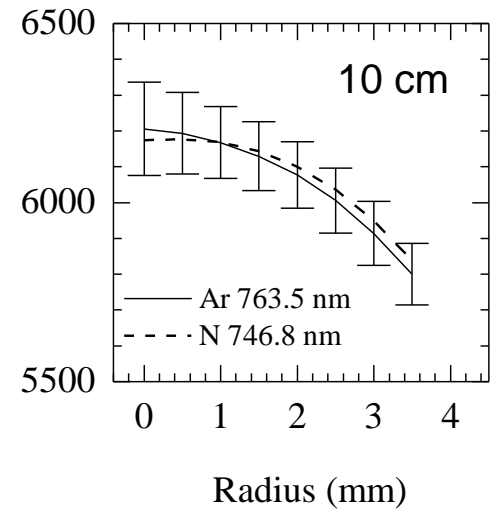

(b)

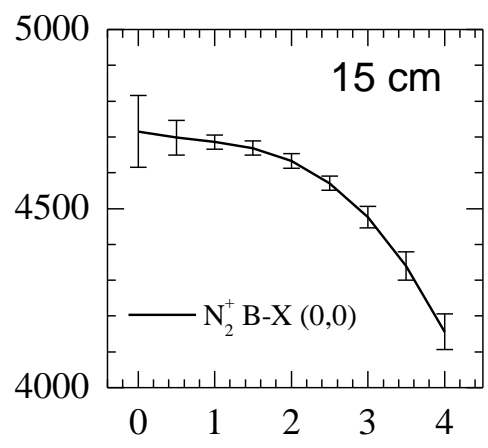

(c)

Figure 10. Radial Temperature Profiles of the $\mathrm{N}_{2} / \mathrm{Ar}$ Plasma Experiments at nozzle exit $(0 \mathrm{~cm})$ and at the exit of the 10 and $15 \mathrm{~cm}$ test sections. 


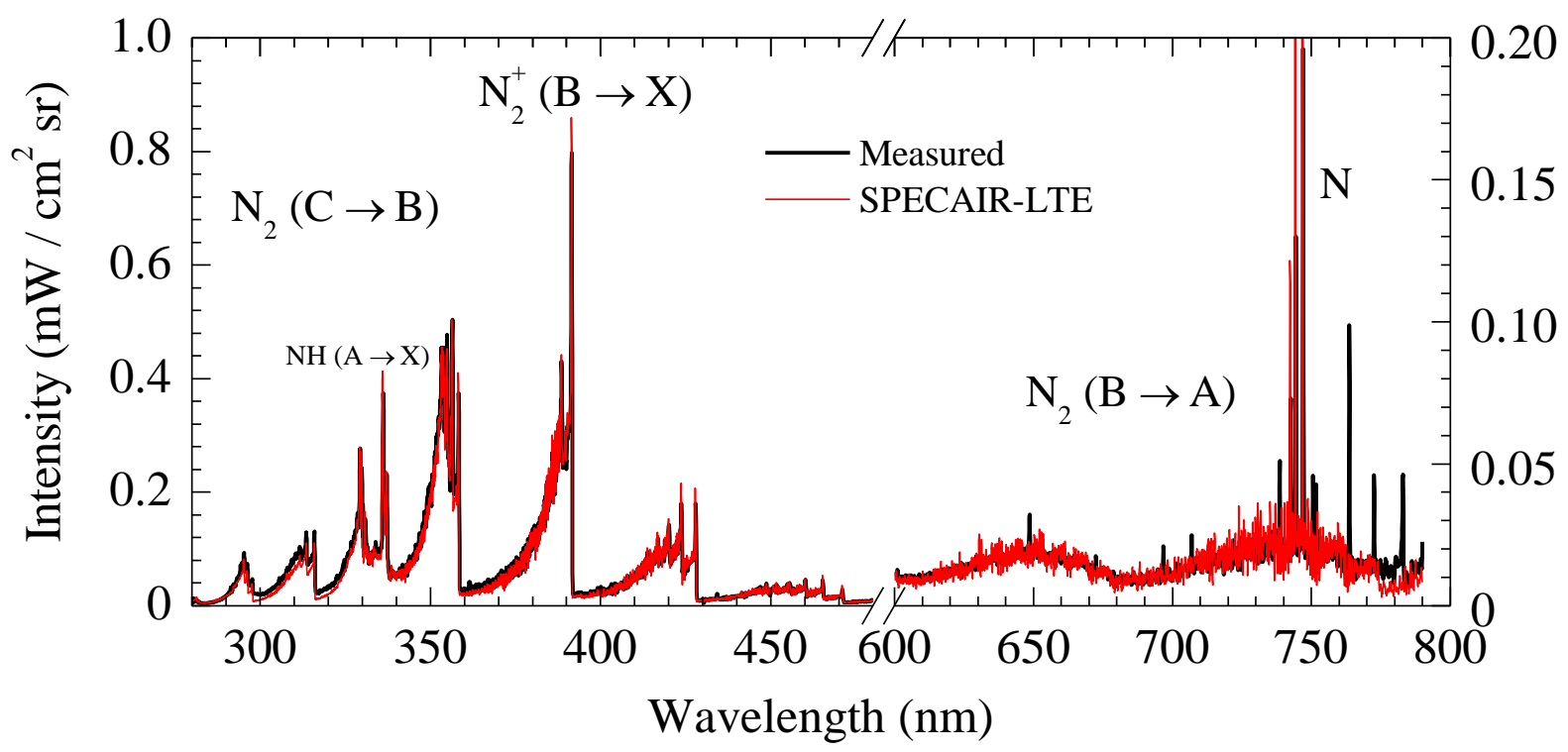

Figure 11. Measured and computed LTE spectra of the nitrogen/argon plasma at the nozzle exit. Several argon lines appear between 650 and $800 \mathrm{~nm}$ (not modeled in SPECAIR). 


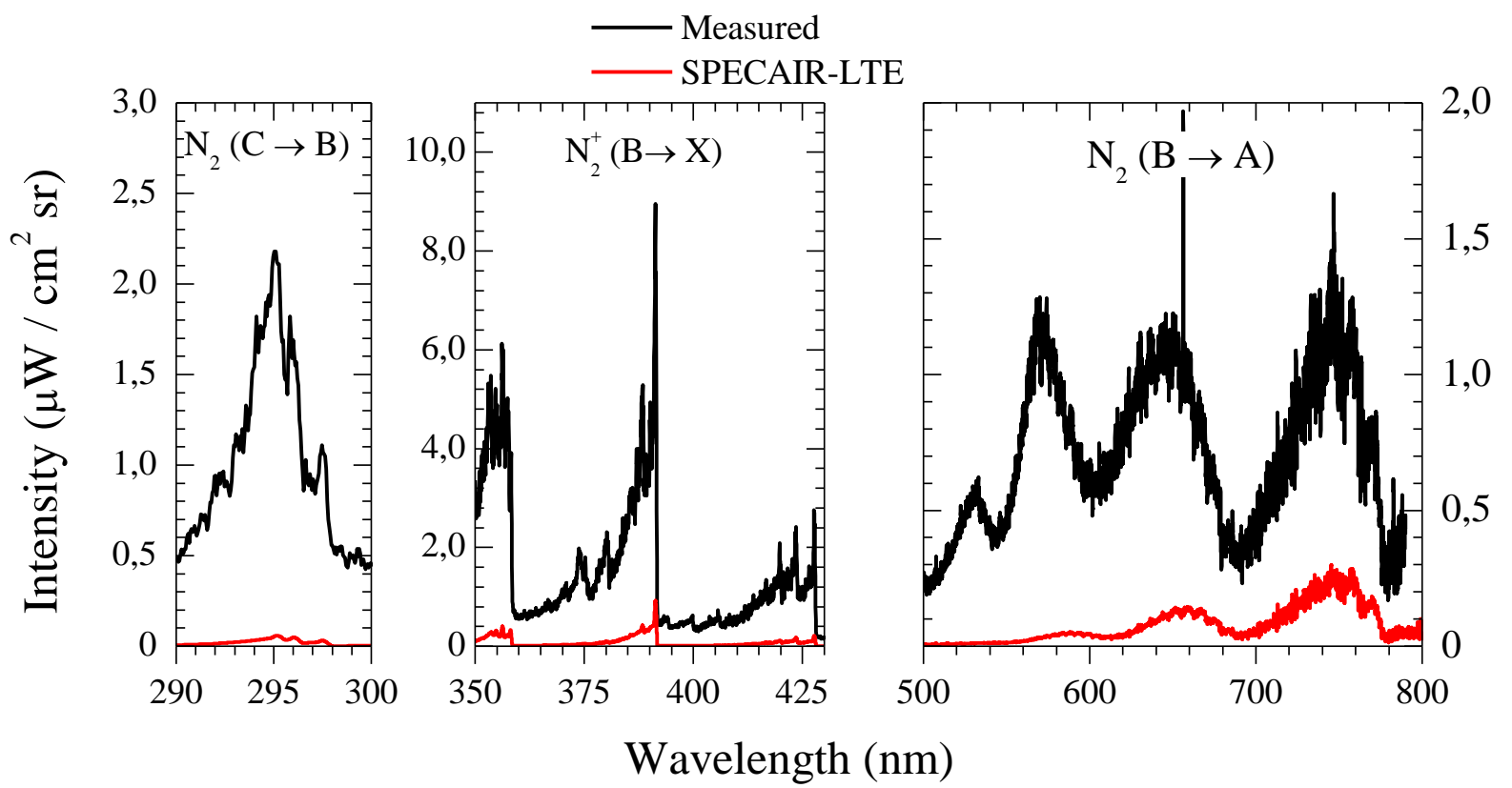

Figure 12. Measured and computed LTE spectra of the nitrogen/argon plasma at the exit of the 15-cm testsection. 


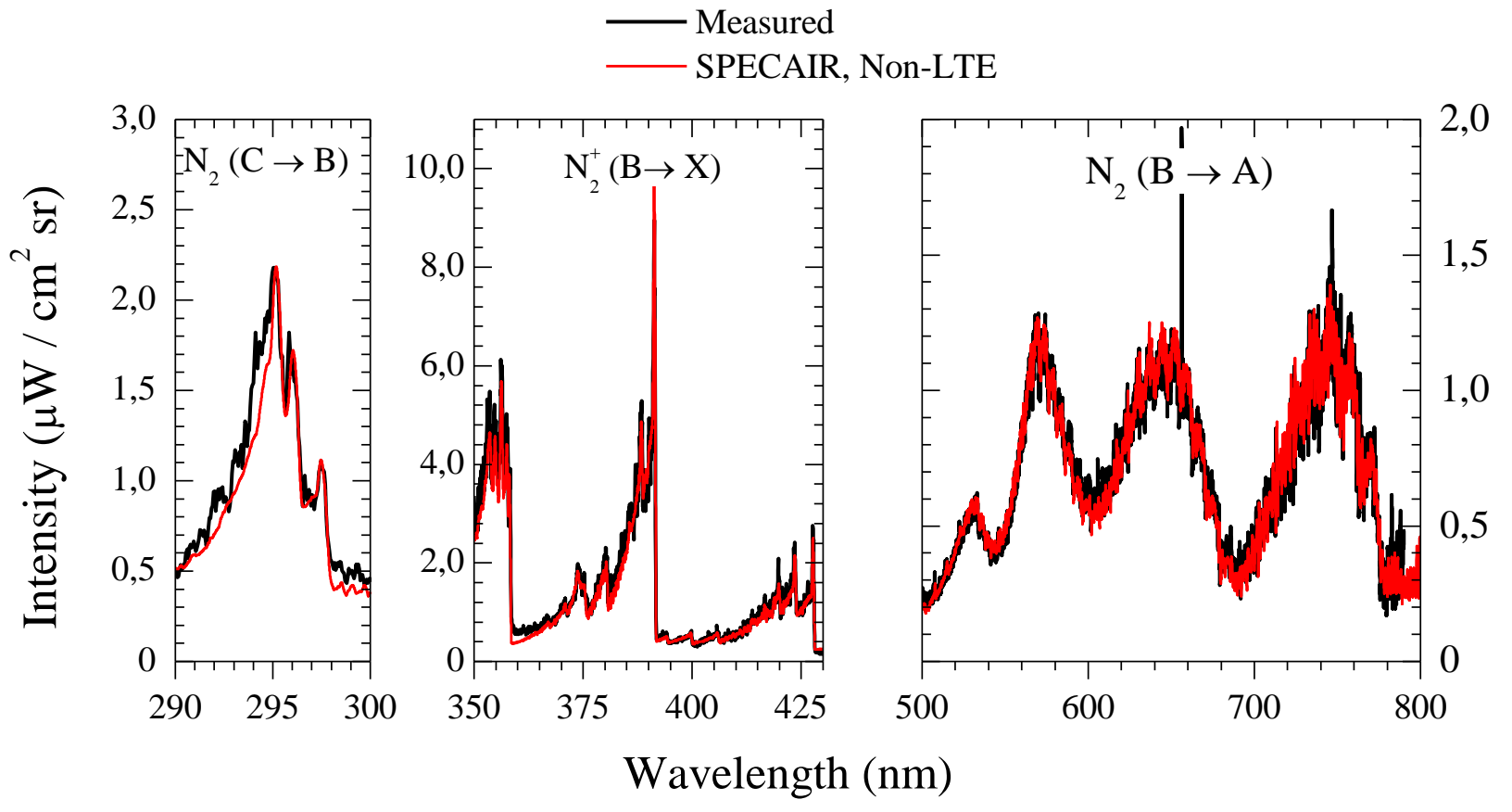

Figure 13. Measured and computed non-LTE (i.e. using the overpopulation factors shown in Figure 6) spectra of the nitrogen/argon plasma at the exit of the $15-\mathrm{cm}$ test-section. Note that the $\mathrm{H}_{\alpha}$ line at $656 \mathrm{~nm}$ is not modeled in SPECAIR. 


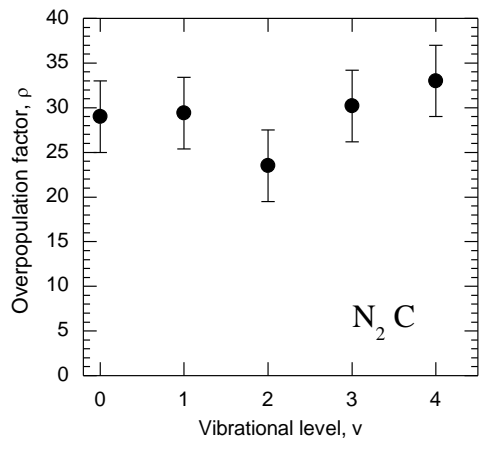

(a)

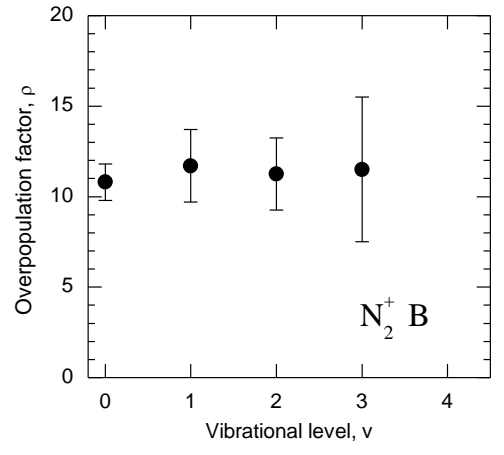

(b)

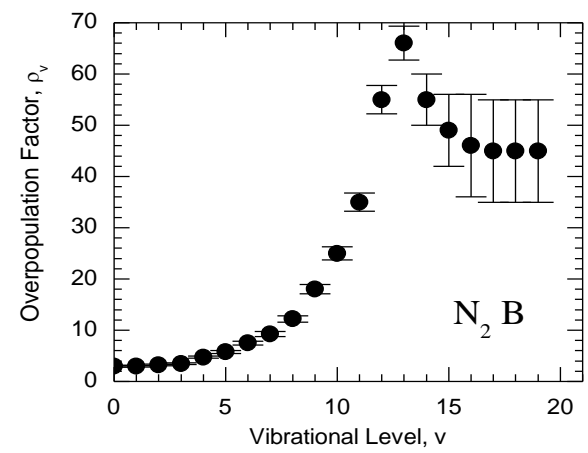

(c)

Figure 14. Measured vibrational overpopulation factor distributions in the recombining $\mathrm{N}_{2} / \mathrm{Ar}$ plasma. a) $\mathrm{N}_{2}$ C state, b) $\mathrm{N}_{2}{ }^{+}$B state, c) $\mathrm{N}_{2}$ B state 


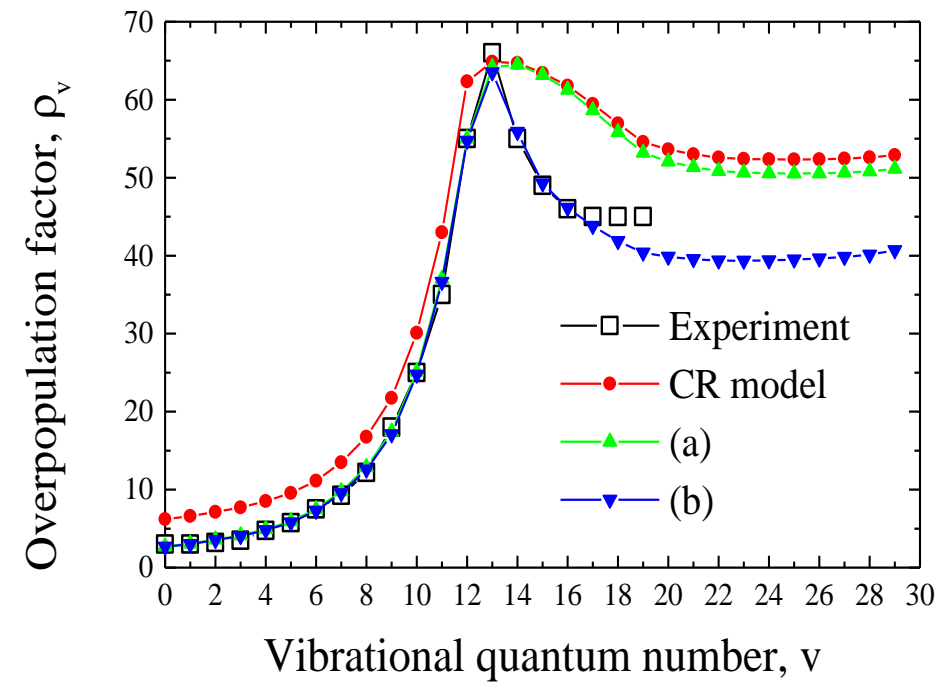

Figure 15. Vibrational overpopulation factors of the $\mathrm{N}_{2} \mathrm{~B}$ state. $\mathrm{CR}$ model calculation performed with $T=4715 \mathrm{~K}, p=1 \mathrm{~atm}, \rho_{e}=180, \rho_{\mathrm{N}}=8.1$. (a): CR model with $\mathrm{N}_{2}(\mathrm{X}-\mathrm{A})$ and $\mathrm{N}_{2}(\mathrm{X}-\mathrm{B})$ electron-impact excitation rates multiplied by 4 and the $N_{2}(B, v=12)$ predissociation rate divided by 5 . (b): same as (a) without predissociation of levels $v \geq 14$ of $\mathrm{N}_{2}(\mathrm{~B})$. 


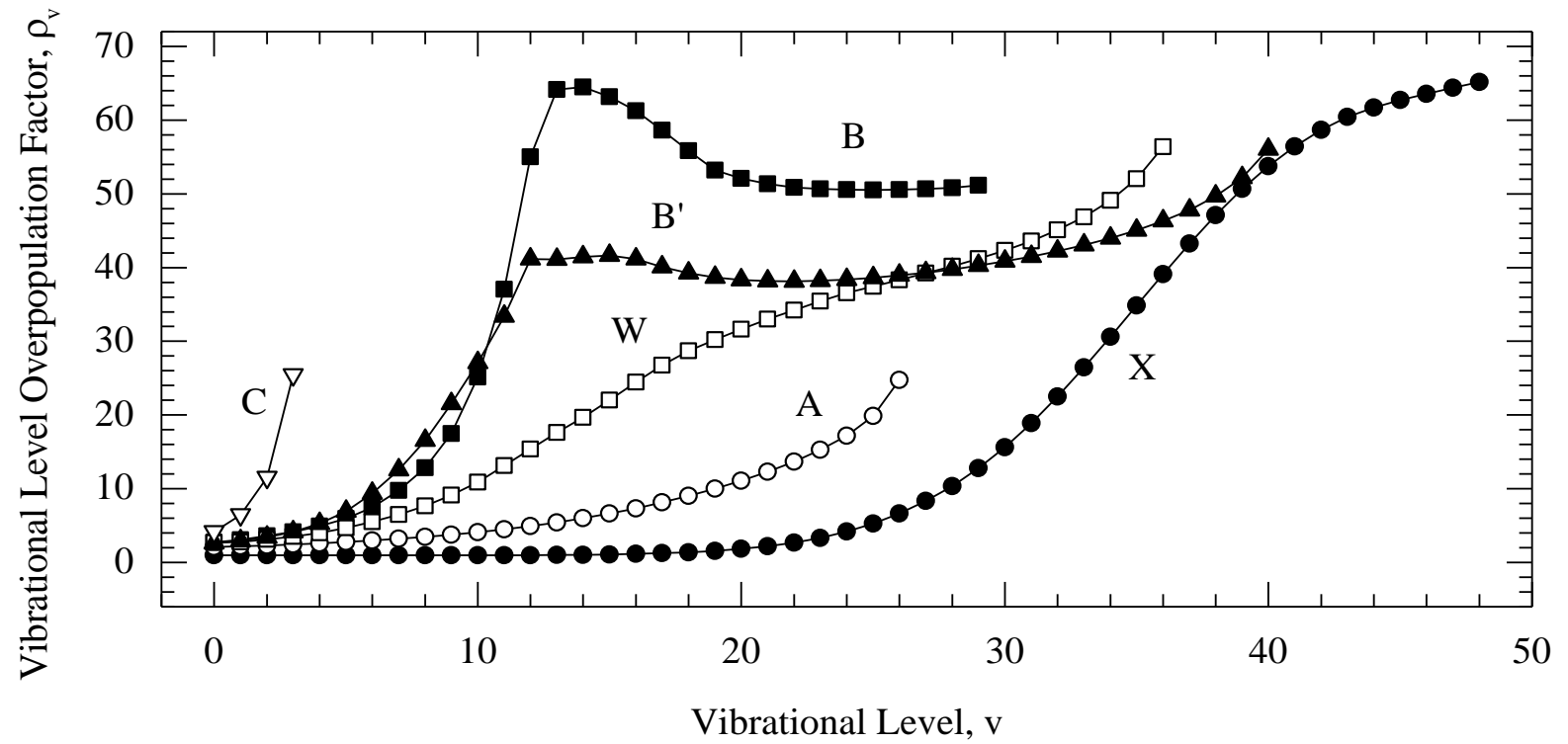

Figure 16. Vibrational overpopulation factors of the $X, A, B, W, B^{\prime}$ and $C$ states of $N_{2}$. Same conditions as curve (a) of [insert Figure 7. 

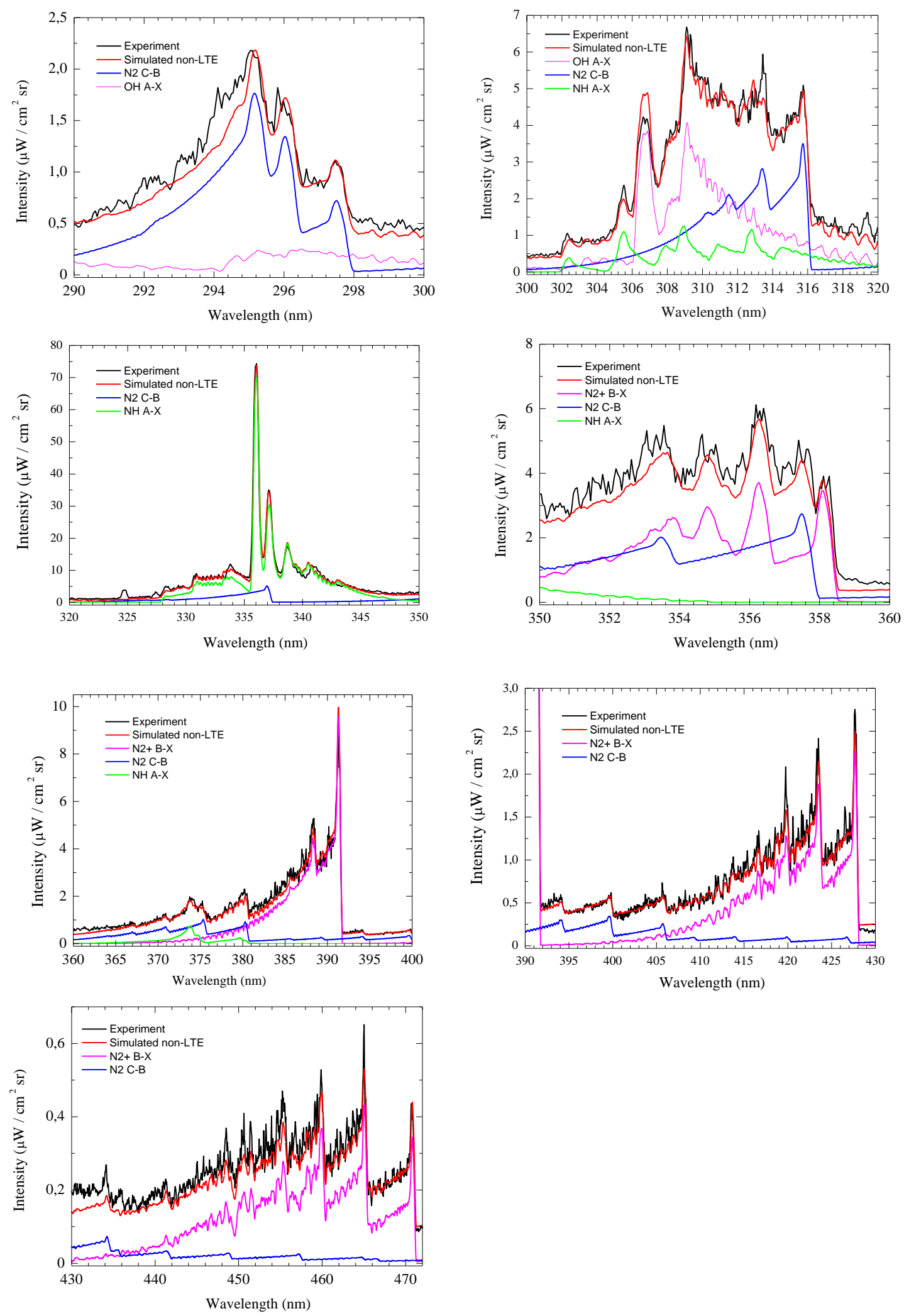

Figure A.1. Details of the spectral fits at the exit of the $15-\mathrm{cm}$ test-section 